\title{
RESEARCH
}

Open Access

\section{Early postpartum dyslipidemia and its potential predictors during pregnancy in women with a history of gestational diabetes mellitus}

Ling Pei ${ }^{1}$, Huangmeng Xiao ${ }^{1}$, Fenghua Lai ${ }^{1}$, Zeting $\mathrm{Li}^{1}$, Zhuyu Li ${ }^{2}$, Shufan Yue ${ }^{1}$, Haitian Chen ${ }^{2}$, Yanbing Li ${ }^{1}$ and Xiaopei $\mathrm{CaO}^{1 *}$

\begin{abstract}
Background: This study aimed to analyze the incidence of early postpartum dyslipidemia and its potential predictors in women with a history of gestational diabetes mellitus (GDM).

Methods: This was a retrospective study. Five hundred eighty-nine women diagnosed with GDM were enrolled and followed up at 6-12 weeks after delivery. A $75 \mathrm{~g}$ oral glucose tolerance test (OGT) and lipid levels were performed during mid-trimester and the early postpartum period. Participants were divided into the normal lipid group and dyslipidemia group according to postpartum lipid levels. Demographic and metabolic parameters were analyzed. Multiple logistic regression was performed to analyze the potential predictors for early postpartum dyslipidemia. A receiver operating characteristic curve (ROC) was calculated to determine the cut-off values.

Results: A total of $38.5 \%$ of the 589 women developed dyslipidemia in early postpartum and $60 \%$ of them had normal glucose metabolism. Delivery age, systolic blood pressure (SBP), glycated hemoglobin (HbA1c) and lowdensity lipoprotein cholesterol (LDL-C) were independent predictors of early postpartum dyslipidemia in women with a history of GDM. The cut-offs of maternal age, SBP, HbA1c values, and LDL-C levels were 35 years, $123 \mathrm{mmHg}$, $5.1 \%$, and $3.56 \mathrm{mmol} / \mathrm{L}$, respectively. LDL-C achieved a balanced mix of high sensitivity (63.9\%) and specificity (69.2\%), with the highest area under the receiver operating characteristic curve (AUC) (0.696). When LDL-C was combined with age, SBP, and $\mathrm{HbA1c}$, the AUC reached to 0.733 .

Conclusions: A lipid metabolism evaluation should be recommended in women with a history of GDM after delivery, particularly those with a maternal age $>35$ years, $\mathrm{SBP}>123 \mathrm{mmHg}$ before labor, HbA1c value $>5.1 \%$, or $\mathrm{LDL}-\mathrm{C}$ levels $>3.56 \mathrm{mmol} / \mathrm{L}$ in the second trimester of pregnancy.
\end{abstract}

Keywords: Gestational diabetes mellitus, Predictor, Lipid, postpartum, Cardiovascular disease

\footnotetext{
* Correspondence: caoxp@mail.sysu.edu.cn

'Department of Endocrinology, First Affiliated Hospital, Sun Yat-sen University, 58 Zhongshan 2nd Rd, Guangzhou 510080, China

Full list of author information is available at the end of the article
}

(c) The Author(s). 2020 Open Access This article is licensed under a Creative Commons Attribution 4.0 International License, which permits use, sharing, adaptation, distribution and reproduction in any medium or format, as long as you give appropriate credit to the original author(s) and the source, provide a link to the Creative Commons licence, and indicate if changes were made. The images or other third party material in this article are included in the article's Creative Commons licence, unless indicated otherwise in a credit line to the material. If material is not included in the article's Creative Commons licence and your intended use is not permitted by statutory regulation or exceeds the permitted use, you will need to obtain permission directly from the copyright holder. To view a copy of this licence, visit http://creativecommons.org/licenses/by/4.0/ The Creative Commons Public Domain Dedication waiver (http://creativecommons.org/publicdomain/zero/1.0/) applies to the data made available in this article, unless otherwise stated in a credit line to the data. 


\section{Background}

Cardiovascular disease (CVD) is currently the leading cause of mortality. CVD accounts for up to $40 \%$ of all deaths in the urban and rural populations in China [1]. There has been a trend in stagnation in cardiovascular mortality rates in young adults, especially in women, even though the overall cardiovascular mortality rate has markedly decreased over the past decades [2]. Therefore, the recommendation for screening of CVD risk to be started at the age of 20 years, and revisited every 4-6 years to prevent cardiovascular events [3, 4].

Gestational diabetes mellitus (GDM) is a common pregnancy complication that is strongly associated with adverse maternal and offspring events. Currently, the incidence of GDM in mainland China ranges $14.8-17.6 \%$ $[5,6]$. Overweight or obesity before pregnancy is one of the leading contributors to GDM [7]. Furthermore, the maternal diet during pregnancy is not only relevant for fatty acid supply during fetal life [8], but also for development of GDM. GDM can be caused by a diet low in carbohydrates, but high in animal fat and protein, as well as an overall 'Western dietary pattern' (high intake of red meat, processed meat, refined grain products, and sweets) [7]. With rapid economic growth and urbanization, the Chinese dietary pattern has become 'Westernized', resulting in an alarming increase in obesity [9]. Notably, in Chinese traditional practices, pregnant woman should eat more eggs and meat to supplement nutrition.

Women with a history of GDM have a much higher risk of postpartum diabetes [10, 11], as well as other CVDrelated risk factors, including dyslipidemia [12-15] and metabolic syndrome [16]. As a result, the incidence of CVD in women with a history of GDM is 2-3-fold higher than in those without GDM [17-20]. Dyslipidemia is a major independent modifiable risk factor of atherosclerosis. A previous study showed that the prevalence of postpartum dyslipidemia in women with GDM was 52\% [13] and women with GDM had a 1.4-1.8-fold risk for dyslipidemia compared with their peers [14]. These findings indicate that postpartum dyslipidemia is also a serious health problem in women with GDM. Professional guidelines recommend that all women with GDM should have glucose metabolism examined at 4-12 weeks after delivery, but the risk of postpartum dyslipidemia has not been put on the agenda [21]. To date, there were few studies focused on the risk of postpartum dyslipidemia and the potential predictors were seldom reported. Therefore, the present study aimed to examine the potential risk factors during pregnancy affecting abnormal postpartum lipid metabolism.

\section{Methods}

\section{Participants}

Women who were diagnosed with GDM as shown by a 75-g 2-h oral glucose tolerance test (OGTT) that was performed during 24-28 weeks of pregnancy were collected. All of the women received intensive lifestyle intervention, and insulin was used for those who failed in lifestyle intervention. Participants were followed up at 6-12 weeks after delivery. Inclusion criteria were as follows: (1) age of 18-45 years; (2) a diagnosis of GDM with a $75 \mathrm{~g}$ 2-h OGTT during 24-28 weeks of pregnancy; (3) plasma lipid was measured at the second or third trimester; and (4) women received a 75-g 2-h OGTT and plasma lipid measurements 6-12 weeks after delivery. Exclusion criteria were as follows: (1) patients diagnosed with overt diabetes during pregnancy; (2) patients suffered from subclinical or overt hyperthyroidism/hypothyroidism; and (3) patients complicated with chronic liver and kidney diseases.

\section{Data collection}

Demographic characteristics, basic anthropometry, and glucose and lipid levels during pregnancy and after delivery were recorded. Specifically, gestational age, past medical history, a history of family diabetes, pre-pregnancy weight, weight gain during pregnancy, systolic blood pressure (SBP) / diastolic blood pressure (DBP) before labor glycated hemoglobin (HbA1c) levels, fasting plasma glucose (FPG), $1 \mathrm{~h}$ plasma glucose (1 h PG) and $2 \mathrm{~h}$ plasma glucose (2 h PG) levels of a 75-g OGTT, total cholesterol (TC) levels, triglyceride (TG) levels, high-density lipoprotein cholesterol (HDL-C) levels, and low-density lipoprotein cholesterol (LDL-C) levels were recorded.

\section{Definitions of GDM and dyslipidemia}

The diagnosis of GDM was based on the International Association of Diabetes and Pregnancy Study Groups criteria [22] in which any of the three items following 75-g OGTT were reached: FPG levels $>5.1 \mathrm{mmol} / \mathrm{L}$ and $<7.0 \mathrm{mmol} / \mathrm{L}, 1 \mathrm{~h}$ PG levels $\geq 10.0 \mathrm{mmol} / \mathrm{L}$, and $2 \mathrm{~h}$ PG levels $\geq 8.5 \mathrm{mmol} / \mathrm{L}$ and $<11.1 \mathrm{mmol} / \mathrm{L}$.

Postpartum dyslipidemia was defined in accordance with the Third Report of the National Cholesterol Education Program (NCEP) Expert Panel on Detection, Evaluation, and Treatment of High Blood Cholesterol in Adults (Adult Treatment Panel III) final report (NCEPATP III) [23] as follows: TC levels $\geq 6.22 \mathrm{mmol} / \mathrm{L}$, TG levels $\geq 2.26 \mathrm{mmol} / \mathrm{L}$, LDL-C levels $\geq 4.14 \mathrm{mmol} / \mathrm{L}$, and HDL-C levels $\leq 1.04 \mathrm{mmol} / \mathrm{L}$.

World Health Organization 1999 criteria [24] were used to assess postpartum glucose metabolism of the subjects. Diabetes was diagnosed when FPG levels were $\geq 7.0 \mathrm{mmol} / \mathrm{L}, 2 \mathrm{~h}$ PG levels were $\geq 11.1 \mathrm{mmol} / \mathrm{L}$, or random venous blood glucose levels were $\geq 11.1 \mathrm{mmol} / \mathrm{L}$. Subjects without typical symptoms of diabetes were tested again on the following day. Impaired fasting glucose (IFG) was diagnosed as FPG levels $\geq 6.1 \mathrm{mmol} / \mathrm{L}$ and $<7.0 \mathrm{mmol} / \mathrm{L}$ and $2 \mathrm{~h}$ PG levels $<7.8 \mathrm{mmol} / \mathrm{L}$. 
Impaired Glucose tolerance (IGT) was defined as FPG levels $<6.1 \mathrm{mmol} / \mathrm{L}$ and $2 \mathrm{~h}$ PG levels $\geq 7.8 \mathrm{mmol} / \mathrm{L}$ and $<$ $11.1 \mathrm{mmol} / \mathrm{L}$.

\section{Statistical analysis}

Statistical analysis was carried out using SPSS version 22.0 software (IBM Corp, Armonk, NY, USA). Nonnormally distributed variables are presented as medians with interquartile ranges, and categorical data are expressed as percentages. Data were compared by the unpaired $t-$ test or Mann-Whitney U test where appropriate. Categorical variables were compared using the chi-square test. Logistic regression models were used to assess the potential predictors and then adjusted for $1 \mathrm{~h}$ PG, TC, TG, HDL-C, and the TG/HDL-C ratio during pregnancy. The receiver operating characteristic (ROC) curve was performed to determine the cut-off values of postpartum dyslipidemia in GDM women. The overall predictability of predictors was assessed using the area under the ROC (AUC). $P<0.05$ was considered statistically significant.

\section{Results}

A total of 589 pregnant women with GDM were enrolled and finished their postpartum visit in this study. A total of 227 (38.5\%) of these women were diagnosed with dyslipidemia and 209 (35.5, 32.4\% with prediabetes and $3.1 \%$ with diabetes) were diagnosed with abnormal glucose tolerance at 6-12 weeks after delivery. A total of $23.1 \%$ of participants had dyslipidemia with normal glucose tolerance, which accounted for up to $60 \%$ of dyslipidemia. A total of $15.49 \%$ (13.6\% with prediabetes and $1.89 \%$ with diabetes) of participants had both postpartum glucose intolerance and dyslipidemia (Fig. 1a). Of these, 195 (33.1\%) had abnormal TC levels, 33 (5.6\%) had abnormal TG levels, 15 (2.5\%) had abnormal HDLC levels, and 127 (21.6\%) had abnormal LDL-C levels. A total of $42.3 \%$ of the participants presented with only one type of dyslipidemia (Fig. 1b). Women with dyslipidemia had an older delivery age, higher levels of SBP, HbA1c, 1 h PG, TC, TG, and LDL-C, a higher TG/HDL$\mathrm{C}$ ratio during pregnancy, higher postpartum glucose levels, and a higher incidence of postpartum glucose intolerance compared with women with normal postpartum lipids (Table 1).

Logistic regression analysis showed that age and SBP, levels of $1 \mathrm{~h}$ PG and $\mathrm{HbA1c}$, the lipid profile (TC, TG, HDL-C, and LDL-C), and the TG/HDL-C ratio during pregnancy were significantly associated with postpartum lipid outcome. The odds ratios (ORs) for these variables ranged 1.047-2.551. Multivariate logistic regression analysis further showed that age $(\mathrm{OR}=1.06,95 \%$ confidence interval $[\mathrm{CI}]$ : $1.014-1.109, P=0.11)$, SBP $(\mathrm{OR}=1.022$, 95\% CI: $1.006-1.038, P=0.006)$, HbA1c $(\mathrm{OR}=1.897$, 95\% CI: $1.119-3.215, P=0.017)$, and LDL-C (OR = 3.671, 95\% CI: $1.386-9.724, P=0.009$ ) were independent predictors of abnormal postpartum lipid metabolism. ROC curves were used to predict dyslipidemia. Sensitivity in the prediction of incident dyslipidemia of each predictor varied from $47.1 \%$ (age) to $63.9 \%$ (LDL-C), and specificity decreased from $69.6 \%$ (SBP) to $57.4 \%$ (HbA1c) across these categories. The cut-offs of age, SBP, HbA1c values, and LDL-C levels were 35 years, $123 \mathrm{mmHg}$, $5.1 \%$, and $3.56 \mathrm{mmol} / \mathrm{L}$, respectively. The AUCs ranged 0.56-0.696 (Table 2).

Generally, LDL-C achieved a balanced mix of high sensitivity and specificity, with the highest area under the AUC (0.696). To improve the overall predictability,
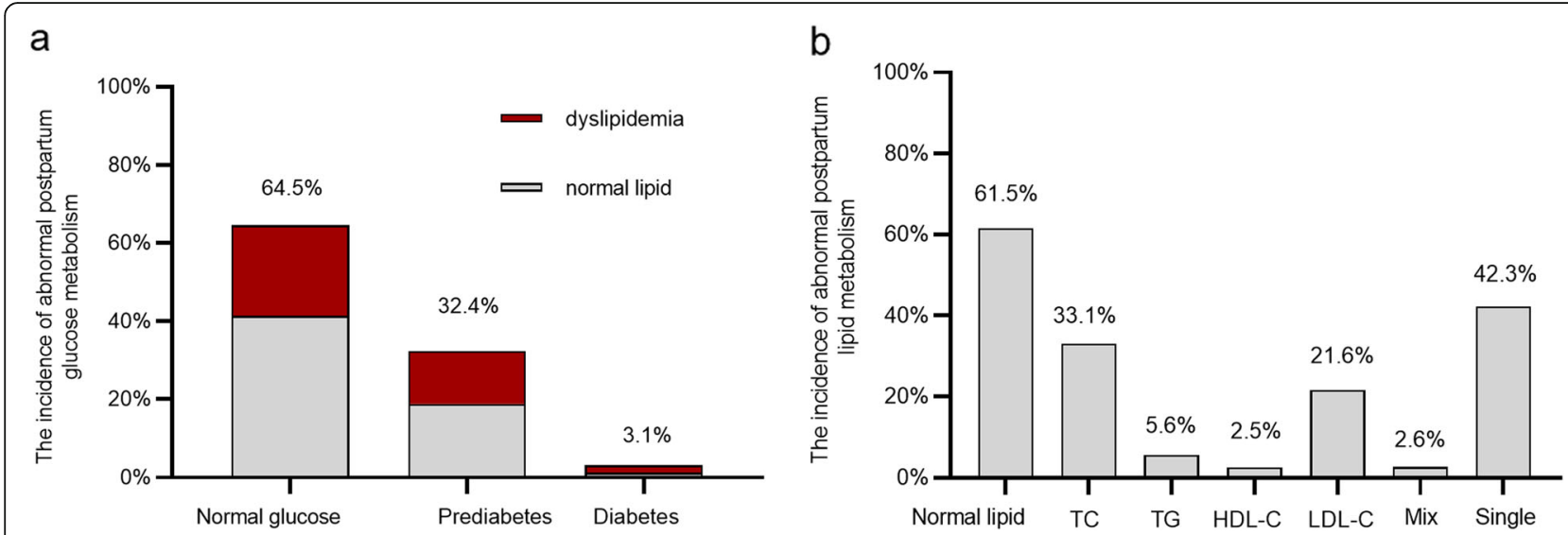

Fig. 1 Glucose and lipid metabolism at 6-12 weeks postpartum in women with GDM. a. The incidence of dyslipidemia among normal glucose, prediabetes and diabetes were 35.8, 42.0 and $61.0 \%$, accounted for the whole participants $23.1,13.6$ and $1.89 \%$, respectively. b. The incidence of different type in dyslipidemia. TC = high TC according to the dyslipidemia definition, TG = high TG according to the dyslipidemia definition, HDL$\mathrm{C}=$ high HDL-C according to the dyslipidemia definition, LDL-C = high LDL-C according to the dyslipidemia definition; Mix = high TC and high TG according to the dyslipidemia definition. Single = presented only one type of dyslipidemia accounted for the whole postpartum dyslipidemia 
Table 1 Basic characteristics of women with history of GDM

\begin{tabular}{|c|c|c|c|}
\hline & Postpartum NLG $(n=362)$ & Postpartum DLG $(n=227)$ & $P$ value \\
\hline Age (years) median (IQR) & $33(30-36)$ & $34(30.5-38)$ & $0.019^{*}$ \\
\hline age $\geq 35, n / \%$ & $149 / 41.2 \%$ & $114 / 50.2 \%$ & 0.057 \\
\hline $\mathrm{BMI}^{\mathrm{a}}(\mathrm{kg} / \mathrm{m} 2)$ median (IQR) & 21.49 (19.59-23.89) & $21.99(20.04-23.82)$ & 0.082 \\
\hline $\mathrm{BMI}^{\mathrm{a}} \geq 24 \mathrm{~kg} / \mathrm{m} 2, \mathrm{n} / \%$ & $81 / 24.6 \%$ & $57 / 23.9 \%$ & 0.375 \\
\hline Weight gain during pregnancy $(\mathrm{kg})$ median (IQR) & $11(8-14)$ & $11(8.8-14.42)$ & 0.384 \\
\hline Family history of diabetes, $\mathrm{n} / \%$ & $93 / 63.3 \%$ & $54 / 36.7 \%$ & 0.582 \\
\hline Insulin history, n/\% & $3 / 0.9 \%$ & $5 / 2.4 \%$ & 0.148 \\
\hline $\mathrm{SBP}(\mathrm{mmHg})$ median $(\mathrm{IQR})$ & $117(110-125)$ & $122(122-129)$ & $0.01^{*}$ \\
\hline DBP (mmHg) median (IQR) & $74(68-79)$ & $74(68-80)$ & 0.299 \\
\hline \multicolumn{4}{|l|}{ 24-28 weeks during pregnancy } \\
\hline FPG (mmol/L), median (IQR) & $4.6(4.3-4.9)$ & $4.6(4.3-5.0)$ & 0.422 \\
\hline $1 \mathrm{~h} \mathrm{PG}(\mathrm{mmol} / \mathrm{L})$, median (IQR) & $9.8(8.8-10.4)$ & $10.0(9.1-10.6)$ & $0.01^{*}$ \\
\hline $2 \mathrm{~h} \mathrm{PG}(\mathrm{mmol} / \mathrm{L})$, median (IQR) & $8.8(8.4-9.3)$ & $8.8(8.35-9.6)$ & 0.194 \\
\hline HbA1C (\%), median (IQR) & $5.0(4.8-5.2)$ & $5.1(4.8-5.3)$ & $0.03^{*}$ \\
\hline $\mathrm{TC}(\mathrm{mmol} / \mathrm{L})$, median $(\mathrm{IQR})$ & $6.0(5.3-6.6)$ & $6.7(6.0-7.5)$ & $0.00^{*}$ \\
\hline $\mathrm{TG}(\mathrm{mmol} / \mathrm{I})$, median (IQR) & $2.15(1.78-2.7)$ & $2.47(1.91-3.17)$ & $0.00^{*}$ \\
\hline HDL-C (mmol/L), median (IQR) & $1.92(1.72-2.16)$ & $1.96(1.69-2.27)$ & 0.06 \\
\hline LDL-C (mmol/L), median (IQR) & $3.28(2.82-3.69)$ & $3.76(3.29-4.29)$ & $0.00^{*}$ \\
\hline TG / HDL-C ratio & $1.13(0.85-1.51)$ & $1.28(0.91-1.75)$ & $0.003^{*}$ \\
\hline \multicolumn{4}{|l|}{ At $6-12$ weeks postpartum } \\
\hline FPG $(\mathrm{mmol} / \mathrm{l})$, median (IQR) & $4.7(4.4-5.0)$ & $4.8(4.6-5.2)$ & $0.00^{*}$ \\
\hline $1 \mathrm{~h} \mathrm{PG}(\mathrm{mmol} / \mathrm{l})$, median (IQR) & $8.5(7.6-9.4)$ & $9.1(8.0-9.9)$ & $0.02^{*}$ \\
\hline 2 h PG (mmol/l), median (IQR) & $6.9(5.8-8.2)$ & $7.4(6.4-8.4)$ & $0.029^{*}$ \\
\hline
\end{tabular}

\section{${ }^{\circ} P<0.05$}

apre-pregancy

NLG Normal lipid group, DLG Dyslipidemia group, IQR Inter-quartile range, BMI Body mass index, SBP Systolic blood pressure, DBP Diastolic blood pressure, TC Total cholesterol, TG Triglycerides, HDL-C High-density lipoprotein cholesterol, LDL-C Low-density lipoprotein cholesterol, FPG Fasting plasma glucose, PG Plasma glucose

Table 2 Logistic analysis of the factors during pregnancy associated with postpartum abnormal lipid metabolism*

\begin{tabular}{|c|c|c|c|c|c|c|c|c|}
\hline & & $\beta$ value & OR $(95 \% \mathrm{Cl})$ & $P$ value & sensitivity & specificity & AUC & Cut-off \\
\hline \multirow[t]{2}{*}{ Age (y) } & crude & 0.048 & $1.047(1.007-1.088)$ & 0.02 & 51.4 & 58 & 0.56 & 35 \\
\hline & adjust & 0.06 & $1.06(1.014-1.109)$ & 0.011 & & & & \\
\hline \multirow[t]{2}{*}{$\mathrm{SBP}(\mathrm{mmHg})$} & crude & 0.023 & $1.023(1.008-1.038)$ & 0.02 & 47.1 & 69.6 & 0.593 & 123 \\
\hline & adjust & 0.022 & $1.022(1.006-1.038)$ & 0.006 & & & & \\
\hline $1 \mathrm{~h} P G$ & crude & 0.159 & $1.172(1.03-1.333)$ & 0.016 & - & - & - & - \\
\hline \multirow[t]{2}{*}{$\mathrm{HbA1c}(\%)$} & crude & 0.717 & $2.069(1.295-3.303)$ & 0.002 & 55.8 & 57.4 & 0.576 & 5.1 \\
\hline & adjust & 0.601 & $1.897(1.119-3.215)$ & 0.017 & & & & \\
\hline $\mathrm{TC}$ & crude & 0.669 & $1.949(1.629-2.331)$ & 0.00 & - & - & - & - \\
\hline TG & crude & 0.46 & 1.566 (1.272-1.928) & 0.00 & - & - & - & - \\
\hline HDL-C & crude & 0.434 & $1.716(1.11-2.654)$ & 0.015 & - & - & - & - \\
\hline \multirow[t]{2}{*}{ LDL-C (mmol/l) } & crude & 0.986 & $2.551(1.969-3.304)$ & 0.00 & 63.9 & 69.2 & 0.696 & 3.56 \\
\hline & adjust & 1.341 & 3.671 (1.386-9.724) & 0.009 & & & & \\
\hline TG / HDL-C & crude & 0.359 & $1.4(1.085-1.087)$ & 0.01 & - & - & - & - \\
\hline
\end{tabular}

${ }^{*}$ The $\mathrm{R}^{2}$ of logistic model was 0.247

crude $=$ simple logistic regression analysis without adjust variables; adjust = Adjusted for the $1 \mathrm{~h}$ PG, TC, TG, HDL-C and TG/HDL-C ratio during pregnancy OR Odds ratio, $C I$ Confidence interval, SBP Systolic blood pressure, AUC Area under the receiver operating characteristic curve, TC Total cholesterol, TG Triglycerides, $L D L-C$ Low-density lipoprotein cholesterol, $1 \mathrm{~h} P G 1 \mathrm{~h}$ plasma glucose 
the AUC was up to 0.733 when all of the independent predictors were combined (Fig. 2).

\section{Discussion}

We for the first time analyzed the prevalence of early postpartum dyslipidemia among Chinese GDM women. This study showed that $38.5 \%$ of women aged $18-45$ years who had a history of GDM developed dyslipidemia at 6-12 weeks postpartum. Approximately $40 \%$ of the women presented with only one type of dyslipidemia. Age, SBP before labor, HbA1c values, and LDL-C levels at 24-28 weeks' gestation were significant independent predictors of early postpartum dyslipidemia. Among them, the cut-offs were 35 years, $123 \mathrm{mmHg}, 5.1 \%$, and $3.56 \mathrm{mmol} / \mathrm{L}$, respectively. The overall predictability (AUC) of LDL-C was 0.696. When LDL-C was combined with age, SBP, and HbA1c, the AUC reached 0.733. The present findings indicated that lipid levels during pregnancy were associated with an increased risk of dyslipidemia after delivery. This finding is consistent with two other studies that also showed a relationship between hypertriglyceridemia in pregnancy and at 6-12 months postpartum $[25,26]$.

In the current study, the incidence of early postpartum dyslipidemia and hyperglycemia were 38.5 and $35.5 \%$, respectively. The proportion of the different types of dyslipidemia in the current study is similar to that in another multi-ethnic study, which showed an overall prevalence of postpartum dyslipidemia of $52 \%$ at 6 weeks postpartum [13]. Moreover, $23.1 \%$ of participants had dyslipidemia, but normal postpartum glucose tolerance. This finding suggested that approximately one in four women with a history of GDM were mistakenly considered as "normal" if only postpartum glucose metabolism was measured. Furthermore, nearly one in six women had both postpartum abnormal glucose tolerance and an abnormal lipid profile, which indicated a high risk of CVD among these young mothers. Previous studies have shown that full adherence to the ATP III Primary Prevention Guidelines would prevent 20,000 myocardial infarctions and 10,000 deaths from coronary heart disease per year in adults [27]. Additionally, 1 $\mathrm{mmol} / \mathrm{L}$ reduction in LDL-C levels could prevent 11 per 1000 major vascular events over 5 years for individuals with a 5-year risk of major vascular events $<10 \%$ [28]. Notably, more preventive efforts need to be taken for young patients with multiple risk factors for CVD who would benefit most from early cardioprotective interventions [29]. Accordingly, screening and management of dyslipidemia among these young mothers with a history of GDM at early postpartum could also be beneficial for preventing long-term CVD.

However, women with GDM have poor compliance with postpartum evaluation and the rate of postpartum review is low [30, 31]. Therefore, this study examined predictors of dyslipidemia during pregnancy in women at early postpartum to raise awareness for management of early postpartum dyslipidemia. In line with previous studies [32, 33], the present study showed that age and SBP were independent risk factors for postpartum dyslipidemia. Age may be a predisposing factor for dyslipidemia owing to TC, TG, and other lipoprotein levels increasing with aging $[34,35]$. Remarkably, aging is associated with insulin resistance and reduced pancreatic $\beta$ cell reserve, which appears to cause exacerbated adipose tissue lipolysis [36]. Hypertensive disorders of pregnancy

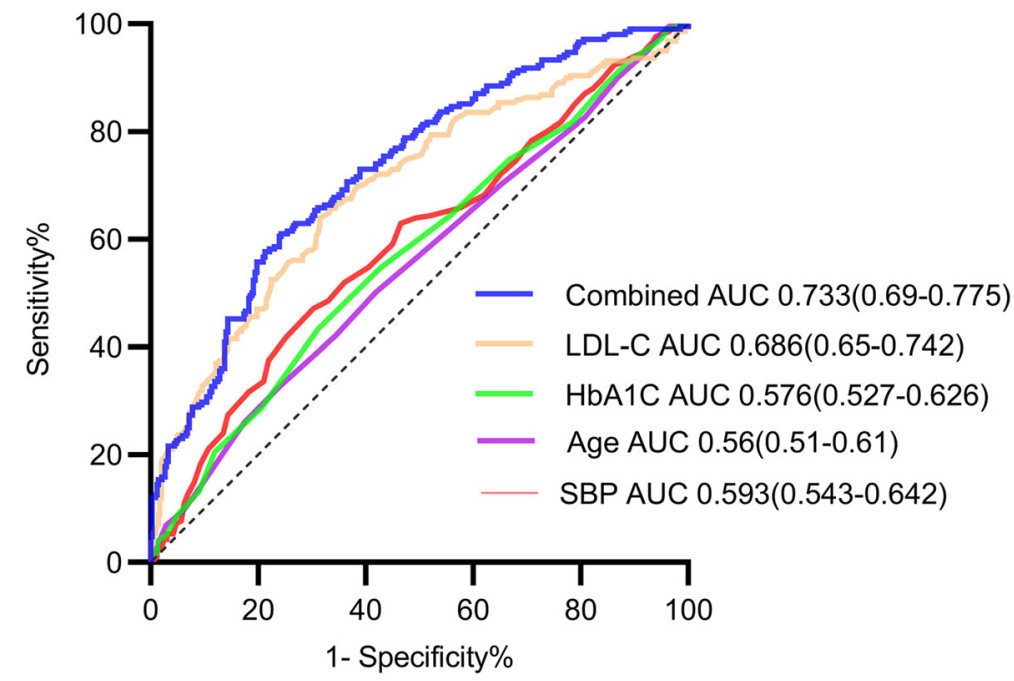

Fig. 2 ROC curves. ROC curves showing the capacity to predict incident dyslipidemia of age, SBP before labor, HbA1C, LDL-C at gestational 2428 weeks and combined overall. $\mathrm{ROC}=$ receiver operating characteristic. $\mathrm{AUC}=$ area under the ROC curve. SBP $=\mathrm{Systolic}$ blood pressure. $\mathrm{LDL}-\mathrm{C}=$ low-density lipoprotein cholesterol. Combined = age $+\mathrm{SBP}+\mathrm{HbA} 1 \mathrm{C}+\mathrm{LDL}-\mathrm{C}$ 
are also recognized as a risk of an adverse lipid profile after pregnancy [32]. As a result, guidelines recommended lipid screening for all women with a history of hypertensive disorders of pregnancy [37]. Moreover, the current study showed that HbA1c values and LDL-C levels at 2428 weeks' gestation were independent risk factors, and the level of LDL-C was the most important predictor of dyslipidemia. Patients with LDL-C levels $>3.56 \mathrm{mmol} / \mathrm{L}$ had relatively balanced sensitivity (63.9\%) and specificity (69.2\%) and had the best AUC (0.696). However, the precise mechanisms involved remain to be determined.

Management of glucose and lipids during pregnancy may provide a chance to reduce development of dyslipidemia postpartum. The ORs for age, SBP, HbA1c, and LDL-C were $1.06,1.022,1.897$, and 3.671, respectively, in the present study. Therefore, LDL-C levels during pregnancy are the most relevant to onset of dyslipidemia after delivery, followed by HbA1c. Plasma LDL-C levels can be measured directly or calculated using the Friedewald formula as follows: LDL-C $=\mathrm{TC}-\mathrm{HDL}-\mathrm{C}-$ - TG/ 2.2) in $\mathrm{mmol} / \mathrm{L}$. The outcome is the same in the absence of high TG levels [38]. LDL-C induces apoptosis and decreases proliferation and maximal glucose-stimulated insulin secretion in murine and human $\beta$-cells [39]. Multiple stepwise regression analysis also showed that LDL-C and HbAlc were independent risk factors for the development of insulin resistance after delivery in Chinese women with a history of GDM [40]. Therefore, optimal levels of glucose and lipids during pregnancy might reduce insulin resistance and improve pancreatic $\beta$-cell function to decrease postpartum dyslipidemia. Maternal dyslipidemia and/or obesity affects obesity and metabolic diseases in the offspring, including changes in cardiac geometry and function [41, 42]. Hyperlipidemia induces a proinflammatory cascade, which can regulate placental nutrient transporters and affect placental development and function, fatty acid composition, oxidative stress, inflammatory stress, and adaptive immunity [43]. Obesity is implicated in increased levels of placental inflammatory markers and lipid esterification, and altered levels of maternal adipokines. This may play a role in long-term insulin resistance of offspring [44]. Additionally, dyslipidemia and obesity reduce n-3 long-chain polyunsaturated fatty acid in tissue, which is a type of fatty acid and signaling molecule acting on intracellular sensing systems to alter embryonic and fetal development. This results in long-term effects on the offspring [45]. More data are required to further verify our hypothesis in future.

\section{Study strength and limitations}

This study found that age, SBP before labor, HbA1c and LDL-C in the second trimester of pregnancy were the potential predictors in women with history of GDM, and also has a few limitations. First, the results were based on a fairly short follow-up period and all participants were from a single center. Second, a retrospective study may result in selective bias and incomplete clinical data. Finally, some characteristics of the subjects were lacking, such as breastfeeding, diet, and physical activity, which might affect glucolipid metabolism during pregnancy and postpartum. Therefore, a long-term follow-up and large-scale multicenter study for validation of our results should be performed in the future.

\section{Conclusion}

In summary, this study shows a high prevalence of dyslipidemia in women with a history of GDM in the early postpartum period and suggests that postpartum lipid screening might be warranted. Moreover, maternal age, SBP, HbA1c, and LDL-C during pregnancy appear to be independent risk factors for developing postpartum dyslipidemia. This finding suggests that patients with GDM need more intensive treatment and optimal management of glucose, lipids, and blood pressure during pregnancy, which may be beneficial for postpartum metabolism.

\section{Supplementary information}

Supplementary information accompanies this paper at https://doi.org/10. 1186/s12944-020-01398-1.

\section{Additional file 1.}

Additional file 2.

\section{Abbreviations}

GDM: Gestational diabetes mellitus; OGTT: Oral glucose tolerance test; ROC: Receiver operating characteristic curve; SBP: Systolic blood pressure; HbA1c: Glycated hemoglobin; LDL-C: Low-density lipoprotein cholesterol; AUC: Area under the receiver operating characteristic curve;

CVD: Cardiovascular disease; DBP: Diastolic blood pressure; FPG: Fasting plasma glucose; $1 \mathrm{~h}$ PG: $1 \mathrm{~h}$ plasma glucose; $2 \mathrm{~h}$ PG: $2 \mathrm{~h}$ plasma glucose; TC: Total cholesterol; TG: Triglyceride; NCEP: National Cholesterol Education Program; ATP III: Adult Treatment Panel III; IFG: Impaired fasting glucose; IGT: Impaired Glucose tolerance; OR: Odds ratio; Cl: Confidence interval

\section{Acknowledgements}

We are grateful to the participants who took part in the survey.

\section{Authors' contributions}

All authors contributed to study design and interpretation. Ling Pei performed statistical analyses and wrote the first draft of the manuscript. Huangmeng Xiao, Zeting Li, Zhuyu Li, Shufan Yue and Haitian Chen were involved in data collection and processing. Fenghua Lai, Yanbing Li and Xiaopei Cao read, commented on, and approved the final manuscript. Xiaopei Cao is the guarantor of this work and, as such, had full access to all the data in the study and takes responsibility for the integrity of the data and the accuracy of the data analysis. The authors read and approved the final manuscript.

\section{Funding}

This study was supported by grants from the 5010 Project Foundation of Sun Yat-sen University (No. 2017001), National major and development projects (No. 2018YFC1314100) and the Science and Technology Foundation of Guangzhou City (No. 201803010101). 


\section{Availability of data and materials}

All data generated and analyzed in this study are included in this published article. The datasets are available from the corresponding author on reasonable request.

\section{Ethics approval and consent to participate}

The study was approved by the ethics committees for clinical research and animal trials of the First Affiliated Hospital, Sun Yat-sen University (ethical approval numbers: [2017] 124 and [2020] 048). Because of the retrospective nature of this study, informed consent was waived.

\section{Consent for publication}

All authors provide consent for publication of this paper.

\section{Competing interests}

The authors declare no conflict of interest.

\section{Author details}

'Department of Endocrinology, First Affiliated Hospital, Sun Yat-sen University, 58 Zhongshan 2nd Rd, Guangzhou 510080, China. ${ }^{2}$ Department of Obstetrics and Gynecology, First Affiliated Hospital, Sun Yat-sen University, Guangzhou, China.

\section{Received: 2 August 2020 Accepted: 1 October 2020}

Published online: 10 October 2020

\section{References}

1. Wu Y, Benjamin EJ, MacMahon S. Prevention and control of cardiovascular disease in the rapidly changing economy of China. Circulation. 2016;133: 2545-60.

2. Wilmot KA, O'Flaherty M, Capewell S, Ford ES, Vaccarino V. Coronary heart disease mortality declines in the United States from 1979 through 2011: evidence for stagnation in young adults, especially women. Circulation. 2015;132:997-1002.

3. Arnett DK, Blumenthal RS, Albert MA, Buroker AB, Goldberger ZD, Hahn EJ, et al. 2019 ACC/AHA guideline on the primary prevention of cardiovascular disease: a report of the American College of Cardiology/American Heart Association task force on clinical practice guidelines. Circulation. 2019;140: e596-646.

4. Nabel EG. Heart disease prevention in young women: sounding an alarm. Circulation. 2015;132:989-91.

5. Gao C, Sun X, Lu L, Liu F, Yuan J. Prevalence of gestational diabetes mellitus in mainland China: a systematic review and meta-analysis. J Diabetes Invest. 2019;10:154-62.

6. Yan B, Yu Y, Lin M, Li Z, Wang L, Huang P, et al. High, but stable, trend in the prevalence of gestational diabetes mellitus: a population-based study in Xiamen, China. J Diabetes Invest. 2019;10:1358-64.

7. Mclntyre HD, Catalano P, Zhang C, Desoye G, Mathiesen ER, Damm P. Gestational diabetes mellitus. Nat Rev Dis Primers. 2019;5:47.

8. Barrera C, Valenzuela R, Chamorro R, Bascuñán K, Sandoval J, Sabag N, et al. The impact of maternal diet during pregnancy and lactation on the fatty acid composition of erythrocytes and breast Milk of Chilean women. Nutrients. 2018;10:839.

9. Wang Y, Wang L, Qu W. New national data show alarming increase in obesity and noncommunicable chronic diseases in China. Eur J Clin Nutr. 2017;71:149.

10. Bellamy L, Casas JP, Hingorani AD, Williams D. Type 2 diabetes mellitus after gestational diabetes: a systematic review and meta-analysis. Lancet. 2009; 373:1773-9.

11. Song C, Lyu Y, Li C, Liu P, Li J, Ma RC, et al. Long-term risk of diabetes in women at varying durations after gestational diabetes: a systematic review and meta-analysis with more than 2 million women. Obes Rev. 2018;19: 421-9.

12. Ajala O, Jensen LA, Ryan E, Chik C. Women with a history of gestational diabetes on long-term follow up have normal vascular function despite more dysglycemia, dyslipidemia and adiposity. Diabetes Res Clin Pr. 2015; 110:309-14.

13. O'Higgins AC, O'Dwyer V, O'Connor C, Daly SF, Kinsley BT, Turner MJ. Postpartum dyslipidemia in women diagnosed with gestational diabetes mellitus. Irish J Med Sci. 2017;186:403-7.
14. Chodick G, Tenne Y, Barer Y, Shalev V, Elchalal U. Gestational diabetes and long-term risk for dyslipidemia: a population-based historical cohort study. BMJ Open Diabetes Res Care. 2020;8:e870.

15. Retnakaran R, Qi Y, Connelly PW, Sermer M, Hanley AJ, Zinman B. The graded relationship between glucose tolerance status in pregnancy and postpartum levels of low-density-lipoprotein cholesterol and Apolipoprotein B in young women: implications for future cardiovascular risk. J Clin Endocrinol Metab. 2010;95:4345-53.

16. Xu Y, Shen S, Sun L, Yang H, Jin B, Cao X. Metabolic syndrome risk after gestational diabetes: a systematic review and meta-analysis. PLoS One. 2014; 9:e87863.

17. Kessous R, Shoham-Vardi I, Pariente G, Sherf M, Sheiner E. An association between gestational diabetes mellitus and long-term maternal cardiovascular morbidity. Heart. 2013;99:1118-21.

18. McKenzie-Sampson S, Paradis G, Healy-Profitós J, St-Pierre F, Auger N. Gestational diabetes and risk of cardiovascular disease up to 25 years after pregnancy: a retrospective cohort study. Acta Diabetol. 2018;55:315-22.

19. Shah BR, Retnakaran $R$, Booth GL. Increased risk of cardiovascular disease in young women following gestational diabetes mellitus. Diabetes Care. 2008; 31:1668-9.

20. Kramer CK, Campbell S, Retnakaran R. Gestational diabetes and the risk of cardiovascular disease in women: a systematic review and meta-analysis. Diabetologia. 2019;62:905-14.

21. Berger H, Gagnon R, Sermer M. Guideline no. 393-diabetes in pregnancy. J Obstet Gynaecol Can. 2019;41:1814-25.

22. López Stewart G. Diagnostic criteria and classification of hyperglycaemia first detected in pregnancy: a World Health Organization guideline. Diabetes Res Clin Pr. 2014;103:341-63.

23. Expert Panel on Detection E. Executive summary of the third report of the National Cholesterol Education Program (NCEP) expert panel on detection, evaluation, and treatment of high blood cholesterol in adults (adult treatment panel III). JAMA. 2001;285:2486-97.

24. Alberti KG, Zimmet PZ. Definition, diagnosis and classification of diabetes mellitus and its complications. Part 1: diagnosis and classification of diabetes mellitus. Provisional report of a WHO consultation. Diabet Med. 1998;15:539-53.

25. Prados M, Flores-Le Roux JA, Benaiges D, Llauradó G, Chillarón JJ, Paya A, et al. Previous gestational diabetes increases Atherogenic dyslipidemia in subsequent pregnancy and postpartum. Lipids. 2018;53:387-92.

26. Herrera Martínez A, Palomares Ortega R, Bahamondes Opazo R, MorenoMoreno P, Molina Puerta MJ, Gálvez-Moreno MA. Hyperlipidemia during gestational diabetes and its relation with maternal and offspring complications. Nutr Hosp. 2018;35:698-706.

27. Pletcher MJ, Lazar L, Bibbins-Domingo K, Moran A, Rodondi N, Coxson P, et al. Comparing impact and cost-effectiveness of primary prevention strategies for lipid-lowering. Ann Intern Med. 2009;150:243-54.

28. Mihaylova B, Emberson J, Blackwell L, Keech A, Simes J, Barnes EH, et al. The effects of lowering LDL cholesterol with statin therapy in people at low risk of vascular disease: meta-analysis of individual data from 27 randomised trials. Lancet. 2012;380:581-90.

29. Piepoli MF, Hoes AW, Agewall S, Albus C, Brotons C, Catapano AL, et al. 2016 European guidelines on cardiovascular disease prevention in clinical practice. Eur Heart J. 2016;37:2315-81.

30. Bernstein JA, McCloskey L, Gebel CM, Iverson RE, Lee-Parritz A. Lost opportunities to prevent early onset type 2 diabetes mellitus after a pregnancy complicated by gestational diabetes. BMJ Open Diabetes Res Care. 2016:4:e000250.

31. Bernstein JA, Quinn E, Ameli O, Craig M, Heeren T, Lee-Parritz A, et al. Follow-up after gestational diabetes: a fixable gap in women's preventive healthcare. BMJ Open Diabetes Res Care. 2017;5:e000445.

32. Wen C, Metcalfe A, Anderson TJ, Johnson JA, Sigal RJ, Nerenberg KA. Measurement of lipid profiles in the early postpartum period after hypertensive disorders of pregnancy. J Clin Lipidol. 2019;13:1008-15.

33. Veerbeek $J H_{1}$, Hermes W, Breimer AY, van Rijn BB, Koenen SV, Mol BW, et al. Cardiovascular disease risk factors after early-onset preeclampsia, late-onset preeclampsia, and pregnancy-induced hypertension. Hypertension. 2015;65: 600-6.

34. Zhu JR, Gao RL, Zhao SP, Lu GP, Zhao D, Li JJ. 2016 Chinese guidelines for the management of dyslipidemia in adults. J Geriatr Cardiol. 2018;15:1-29.

35. Opoku S, Gan Y, Fu W, Chen D, Addo-Yobo E, Trofimovitch D, et al. Prevalence and risk factors for dyslipidemia among adults in rural and urban 
China: findings from the China National Stroke Screening and prevention project (CNSSPP). BMC Public Health. 2019;19:1500.

36. Chee C, Shannon CE, Burns A, Selby AL, Wilkinson D, Smith K, et al. Relative contribution of Intramyocellular lipid to whole-body fat oxidation is reduced with age but Subsarcolemmal lipid accumulation and insulin resistance are only associated with overweight individuals. Diabetes. 2016; 65:840-50.

37. Anderson TJ, Grégoire J, Pearson GJ, Barry AR, Couture P, Dawes M, et al. 2016 Canadian cardiovascular society guidelines for the management of dyslipidemia for the prevention of cardiovascular disease in the adult. Can J Cardiol. 2016;32:1263-82.

38. Mach F, Baigent C, Catapano AL, Koskinas KC, Casula M, Badimon L, et al. 2019 ESC/EAS guidelines for the management of dyslipidemia: lipid modification to reduce cardiovascular risk. Atherosclerosis. 2019;290:140205.

39. Rütti S, Ehses JA, Sibler RA, Prazak R, Rohrer L, Georgopoulos S, et al. Lowand high-density lipoproteins modulate function, apoptosis, and proliferation of primary human and murine pancreatic $\beta$-cells. Endocrinology. 2009;150:4521-30.

40. Ma Y, Wang N, Gu L, Wei X, Ren Q, Huang Q, et al. Postpartum assessment of the beta cell function and insulin resistance for Chinese women with previous gestational diabetes mellitus. Gynecol Endocrinol. 2019;35:174-8.

41. Khaire A, Wadhwani N, Madiwale S, Joshi S. Maternal fats and pregnancy complications: implications for long-term health. Prostaglandins Leukot Essent Fat Acids. 2020;157:102098.

42. Dong M, Zheng Q, Ford SP, Nathanielsz PW, Ren J. Maternal obesity, lipotoxicity and cardiovascular diseases in offspring. J Mol Cell Cardiol. 2013; 55:111-6.

43. DeRuiter MC, Alkemade FE, Gittenberger-de Groot AC, Poelmann RE, Havekes LM, van Dijk KW. Maternal transmission of risk for atherosclerosis. Curr Opin Lipidol. 2008;19:333-7.

44. Delhaes F, Giza SA, Koreman T, Eastabrook G, McKenzie CA, Bedell S, et al. Altered maternal and placental lipid metabolism and fetal fat development in obesity: current knowledge and advances in non-invasive assessment. Placenta. 2018;69:118-24.

45. Echeverría F, Ortiz M, Valenzuela R, Videla LA. Long-chain polyunsaturated fatty acids regulation of PPARs, signaling: relationship to tissue development and aging. Prostaglandins Leukot Essent Fat Acids. 2016;114: 28-34.

\section{Publisher's Note}

Springer Nature remains neutral with regard to jurisdictional claims in published maps and institutional affiliations.

\section{Ready to submit your research? Choose BMC and benefit from}

- fast, convenient online submission

- thorough peer review by experienced researchers in your field

- rapid publication on acceptance

- support for research data, including large and complex data types

- gold Open Access which fosters wider collaboration and increased citations

- maximum visibility for your research: over $100 \mathrm{M}$ website views per year

At $\mathrm{BMC}$, research is always in progress.

Learn more biomedcentral.com/submissions 